\title{
Which factors make digital learning platforms successful?
}

\author{
Faustmann, Gert; Lemke, Claudia; Kirchner, Kathrin; Monett, Dagmar
}

Published in:

Proceedings of The 13th Annual International Technology, Education and Development Conference

Link to article, DOI:

10.21125/inted.2019.1651

Publication date:

2019

Document Version

Peer reviewed version

Link back to DTU Orbit

Citation (APA):

Faustmann, G., Lemke, C., Kirchner, K., \& Monett, D. (2019). Which factors make digital learning platforms successful? In Proceedings of The 13th Annual International Technology, Education and Development Conference (pp. 6777-6786) https://doi.org/10.21125/inted.2019.1651

\section{General rights}

Copyright and moral rights for the publications made accessible in the public portal are retained by the authors and/or other copyright owners and it is a condition of accessing publications that users recognise and abide by the legal requirements associated with these rights.

- Users may download and print one copy of any publication from the public portal for the purpose of private study or research.

- You may not further distribute the material or use it for any profit-making activity or commercial gain

- You may freely distribute the URL identifying the publication in the public portal 


\title{
WHICH FACTORS MAKE DIGITAL LEARNING PLATFORMS SUCCESSFUL?
}

\author{
Gert Faustmann', Kathrin Kirchner², Claudia Lemke', Dagmar Monett ${ }^{1}$ \\ ${ }^{1}$ Berlin School of Economics and Law (GERMANY) \\ ${ }^{2}$ Technical University of Denmark (DENMARK)
}

\begin{abstract}
Digital and networked technologies infiltrate all aspects of our lives, and thus also how we are consuming and providing knowledge. In particular, digital learning platforms connect the real with the digital place for learning and teaching. They allow for an innovative combination of different learning concepts and learning structures through the consistent use of the possibilities of digitalization. Furthermore, digital learning platforms democratize education because they ensure equal access by heterogeneous user groups through interaction, communication, and sharing of knowledge. Our paper investigates which factors affect the successful use of such platforms for both knowledge consumers and knowledge providers. In particular, we examine the motivations of learners and teachers based on a literature review and an empirical study $(N=486)$. If all participants are taken into consideration, there are various supporting factors but also obstacles to the successful implementation of digital learning platforms. The main goal behind our approach is to understand and describe what contributes to a successful participation in such platforms. As a next step, these success factors might be translated into a set of requirements for a digital learning platform.
\end{abstract}

Keywords: Digital learning platform, extrinsic and intrinsic motivation, learning process lifecycle, success factors.

\section{INTRODUCTION}

Nowadays, teachers meet learners in classrooms who use modern technologies for both learning and leisure activities [1]. Young learners in the higher education area expect social, mobile, user-friendly, instantly, and entertaining knowledge acquisition concepts to achieve an education degree in an effective and efficient way. The border between learning and private use of technologies becomes blurred. Traditional pedagogical methods and concepts where school, university or training are the only place for teaching and learning are no longer applicable. Information Technology (IT), especially the modern digital and networked technologies in the digital age [2], has the potential to transform education itself, the education market with the institutions, commercial providers and the regulations, and, last but not least, the didactical respectively pedagogical concepts [3].

Educational Technology (EdTech) is a wide field with many different perspectives [4]. The definition of EdTech "has evolved over the years as a variation of ways of dealing with learning processes ..., a conceptual framework ..., theory and practice ..., and the latest study and ethical practices of dealing with technological processes and resources" [5]. According to the current definition of the Association for Educational Communications and Technology (AECT), EdTech could be described as "a study and ethical practice of facilitating learning and improving performance by creating, using and managing appropriate technological processes and resources" [6]. Our research on digital learning platforms (DLPs) is oriented towards this perspective in combination with a basic understanding of the digital platform concept, after which educational technology also contains elements of digital technology.

In the next sections we will introduce some related definitions and give an overview of the general determinants of a DLP. Then, we will focus on the analysis of the learning process and on specific motivation factors according to the self-determination theory. An empirical study that was conducted to gather information about how different participants in digital learning technologies perceive DLP's defining characteristics and the factors that contribute to their success is also presented, together with our findings. 


\section{DIGITAL LEARNING PLATFORM SETTINGS}

\subsection{Definitions}

The educational sciences consider the interaction of technology and pedagogy under the heading of media pedagogy [7] or, more specifically, media didactics [8]. This area is an interdisciplinary research field that involves all forms of learning and teaching with the use of analog (e.g. books) and digital media (e.g. videos) technologies [9]. Currently, media didactics is focusing on e-learning. A general definition with a broad acceptance describes e-learning as an umbrella for a variety of digital (multi media) technologies used for teaching and learning to support the process of knowledge transfer with the possibility for interaction and collaboration [8].

E-learning is an expression of a special EdTech perspective [10] that combines concepts, thereby supporting digital technologies for processes and structures with the goal to improve the learning effort. It could substitute the traditional place and time logic of learning and teaching through the use of the Internet. In the case of higher education, the traditional forms of learning and teaching can be innovated by a variety of different EdTech approaches ranging from an educational curriculum outside the classroom to a course, program, or degree completely delivered online. The concrete combination of education and technology is determined by four key features [11] that focus on the specific nature of the technology that is provided [12]:

1) Interaction: The possibility to interact with each other.

2) Multi media: Using of different data formats and their processing for learning and teaching.

3) Multi codality: The existence of different symbol systems in a medium.

4) Multi modality: The parallel use of different sensory channels to transmit information.

Nowadays e-learning became a synonym of many modern forms of learning and teaching by using technology for different concepts, for example online learning or blended learning as a mixed form of online and offline learning. All have the Internet (former WWW or web) as a new form of learning environment in common [13]. Therefore, e-learning could be used as an equivalent to the term digital learning and teaching (see Section 4 for more).

Currently, EdTech and also e-learning are increasingly influenced by the business-oriented view of the platform economy [14]. The idea of a digital platform is based on the construct of multi-sided platforms (MSPs) [15] following the economic principle of two- or multi-sided markets [16, 17]. Afterwards, MSP is any kind of informational intermediary "which gets two or more sides on board and enable interactions between them" [15]. Hagiu and Wright [15] distinguish two key factors describing the specifics of an MSP:

(i) "They enable direct interactions between two or more distinct sides."

(ii) "[E]ach side is affiliated with the platform."

In the educational context there are a lot of different MSPs or (digital) learning platforms (DLP) [18]. The best known and most popular DLPs are education platforms like Coursera or EdX that provide a variety of complete online courses for several thousands of participants at a global scale [19]. Massive Open Online Courses (MOOCs) are already offered by universities worldwide in addition to their regular study programs or as an alternative to certain programs. A MOOC is an "online course aimed at large-scale interactive participation and open access via the web ... and provides interactive user forums that help build a community for the students, professors, and Teaching Assistants" [20]. The education platform provides access to the different courses and offers additional services for affiliating with the platform. By contrast, Learning Management Systems (LMSs) like Moodle are almost always described as digital platforms. LMSs are activity-based and content-oriented and give only a closed group of participants' access to the platform. They are more a complex standard software application family that supports the whole educational content management lifecycle from delivery to administration of course materials in combination with different interaction effects for engaging both learners and teachers [21], but only for a specific university, education institution, or organisation.

\subsection{Determinants of a DLP}

Each concept of a DLP could include the four key factors for e-learning in combination with the opportunities of MSPs. Consequently, a DLP is at first a learning environment that connects teachers 
and learners (two-sided) so that they can interact with each other. Often, DLPs have more than only two participants. For example, they could include educational institutions or a specific service provider for educational technology (multi-sided) [22] (see Fig. 1).

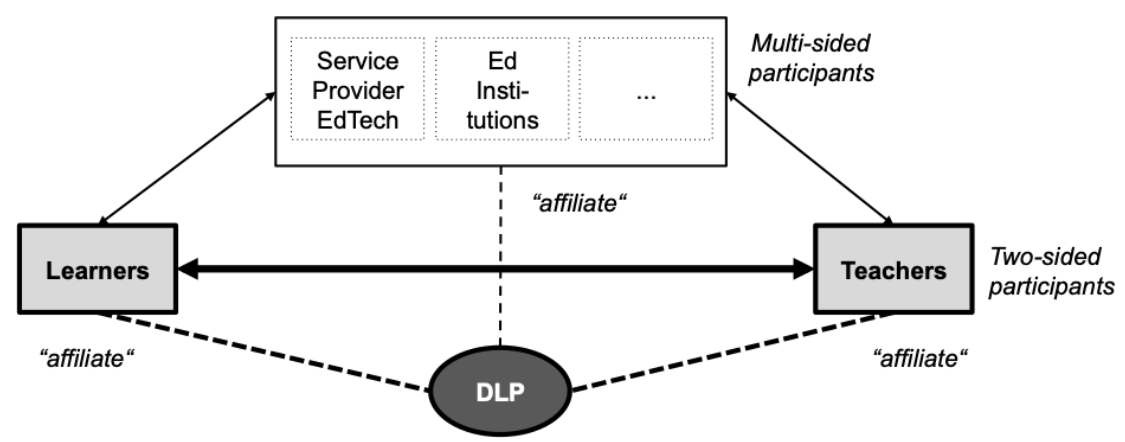

Figure 1. Different sides of a DLP according to [15].

The purpose of a DLP is to provide specific learning and teaching material, more general digital learning and teaching content. This is used as a specific learning and/or teaching concept in combination with technology tools that support the entire or parts of the learning process (see Section 3 for more). The content could be structured as a learning object [23] in the sense of a reusable digital resource facilitating the process [24]. According to the factors of e-learning, learning objects are multi media usable (independable use from a device or an IT infrastructure component) and offer the possibility for a multi codal structure combined with a multi sensual perception. They can be composed of different learning objects (assembled). The facilitating technology of a DLP itself delivers the conceptual conditions that each side could be affiliated to within the platform, such as usability or search functions.

With the focus on communication, interaction, and collaboration between the different participants and groups of a learning environment, DLPs should contain a cultural dimension and a differentiation of a communication and interaction degree [25]. Especially the cultural aspect of learner and teacher groups has a strong influence on the concrete use and acceptance of a learning environment. Regionally limited offers for homogeneous participant groups have different characteristics compared to offers directed at global learning groups determined by factors like social and individual backgrounds [25]. This affects the design of the learning objects for course material or the instructional approaches. In contrast, the communication form considers the differences in the participants' belonging to a group, their active participation, and the associated identification and attachment to these groups. Temporary groups are shaped by the current interest in a topic, while permanent groups already have a connection to the group with common values and beliefs [25]. The interaction mode determines the place for teaching and learning from face-to-face into a classroom to solely online interaction and it focuses on the degree of technology use for the learning environment.

In combination with the conceptual perspective of EdTech understanding, which joint several pedagogical strategies with available technologies [10], DLPs could have further possible dimensions. One dimension addresses the different forms of content use depending on the degree of activity possible for the participants. Therefore, content can be used only for consumption with a low degree of activity or influence through the participant like web-based training for example. In contrast, content could be activity oriented like the use of an intelligent tutoring system [10]. Similarly to the interaction mode, the dimension of computer-mediated communication considers the way in which technology supports learning and teaching. This ranges from wikis for learners or LMSs to the use of specific communication tools such as instants messaging, blogs or videoconferencing. In addition, DLPs should consider the different forms of teaching and learning. This covers the simplest form of teaching - the factual knowledge transfer, where the learner only memorizes the content. The coaching, where the learner needs a high level of social responsibility $[10,26]$, is the most difficult form of teaching. The last dimension focuses on the interaction types defined by the categories of relationship between the different groups [27, 28] of a DLP, here formally learners and teachers.

Fig. 2 shows the determinants of a DLP in the form of a morphological box. This box presents the summary of all dimensions described above. A specific combination of them could shape the design of a DLP. 


\begin{tabular}{|c|c|c|c|c|c|c|}
\hline communication mode & temporary groups & $\begin{array}{l}\text { permanent } \\
\text { groups }\end{array}$ & $\begin{array}{c}\text { meta } \\
\text { communication }\end{array}$ & & & \\
\hline interaction types & $\begin{array}{l}\text { learner-content } \\
\text { interaction }\end{array}$ & $\begin{array}{l}\text { learner-teacher } \\
\text { interaction }\end{array}$ & $\begin{array}{l}\text { learner-learner } \\
\text { interaction }\end{array}$ & $\begin{array}{l}\text { teacher-content } \\
\text { interaction }\end{array}$ & $\begin{array}{l}\text { teacher-teacher } \\
\text { interaction }\end{array}$ & $\begin{array}{l}\text { content-content- } \\
\text { interaction }\end{array}$ \\
\hline interaction mode & classroom & $\begin{array}{l}\text { blended } \\
\text { interaction }\end{array}$ & online interaction & & & \\
\hline cultural context & local & global & & & & \\
\hline content & low activity & activity oriented & & & & \\
\hline $\begin{array}{l}\text { computer-mediated } \\
\text { communication }\end{array}$ & $\begin{array}{l}\text { community } \\
\text { oriented }\end{array}$ & activity based & cognitive tools & $\begin{array}{c}\text { instant } \\
\text { messaging }\end{array}$ & forums and blogs & $\begin{array}{c}\text { video- } \\
\text { conferencing }\end{array}$ \\
\hline teaching/learning forms & transfer & tutoring & coaching & self-determined & team-based & \\
\hline learning objects & learner generated & $\begin{array}{l}\text { teacher } \\
\text { generated }\end{array}$ & assembled & multi media & multi codal & multi modal \\
\hline
\end{tabular}

Figure 2. Morphological box of the DLP.

\section{LEARNING PROCESSES AND MOTIVATION}

For the purpose of determining the success factors of DLPs, the entire learning process must be regarded against the background of the conceptual framework introduced above. It is straightforward that an evaluation can not only refer to the actual learning phase but also has to consider preparatory and follow-up activities. These phases for the implementation of DLP-based learning processes are filled in by different participants who have different goals and, thus, different motivations.

\subsection{Learning process lifecycle}

A distinction should be made between the lifecycle of DLP-based courses and the digital content [29]. The lifecycle of entire courses is initially characterised by the definition of learning objectives and a curriculum. These are defined by institutions, which set the framework for teaching. The content view at the course level is determined by the creation, search, and combination of learning objects. These tasks often fall to the teacher, but can also be completed by other persons or companies. The direct reference to a DLP then takes place through the configuration of the course with the subsequent phases of teaching and assessment. The lifecycle of digital learning content shapes the details of the course's lifecycle. This includes additional activities such as rights management and billing processes.

Gustun and Budaragin summarize the course lifecycle under the phases' concept development, courseware development, and implementation and use [30]. An important partial phase is also mentioned at the end of the lifecycle: the course is evaluated and revisions or adjustments to the concept or content are initiated. This final assessment of success can also be supported by formal evaluation procedures, e.g. within the framework of quality assurance activities such as student surveys. If these assessments are formalised, they may have an influence not only on future courses but also on new concepts for other courses (e.g. when searching for learning objects).

\subsection{Participants in DLP-based learning processes}

The obvious main participants and not only in the digital learning process are learners and teachers. Depending on the phase of the learning process they take on different tasks and roles.

- Zhu, Sun, and Riezebos describe the tasks of the teacher as instructional design, which includes the definition of learning goals, the configuration of a learning environment, and the provision of rules and support [22]. The focus should be on the learner (user-centred), personalized learning should be possible, and collaboration should be supported. In addition, there are tasks to facilitate learning and technical support for learners.

- The learner must be aware of his or her preferences and develop his or her individual learning process. Cooperation in the learning process not only increases learning success, but also prepares the learner for future working relationships. Therefore, the ability to use technology efficiently must be available. 
- In addition, and according to [22], the requirements regarding the two participants are supplemented by a technical viewpoint that makes connecting, ubiquitous, and personalized functions possible in the first place. In addition to face-to-face communication, asynchronous or remote synchronous communication is also supported, there is unhindered access to teaching materials, and the personal preferences of learning can be taken into account. These "roles" of the technology are realized by different applications, which are also offered integrated on DLPs.

\subsection{Motivation Factors}

A DLP can be successful if people are motivated to use it. Therefore, we can look at selfdetermination theory [31]. It is concerned with factors that stimulate certain behaviours and, thus, can give insights into why learners and teachers interact on DLPs. Deci and Ryan distinguish in [31] mainly between two types of motivation - reasons that give rise to an action: extrinsic and intrinsic motivation. Intrinsic motivation is driven by an interest in the task itself or enjoying helping others, that exists in the individual without relying on external pressure or reward. Extrinsic motivation focuses on goal-driven reasons like monetary rewards or career advancement.

The complexity of the successful implementation of learning processes is not only determined by the variety of tasks and roles, but also by the very different backgrounds of those involved in the process. In the first phases of using DLPs, it depends on the scope and diversity of the teaching material that is used. This commitment of the teachers, however, is determined by very personal factors such as attitude (my own assessment of the use of learning objects), subjective norm (what others expect from $\mathrm{me}$ ) and self-efficacy (belief in my own ability to deal with learning objects) [32, 33]. For learners, too, additional factors have an impact on learning success: These include, for example, the learning environment, one's own (learned) learning behaviour or social influences [34]. Just as from the teacher's point of view, psychologically relevant motivational factors such as attitude and expectations regarding one's own learning success can be found among the learners [35].

Matschke and co-authors [36] take a general look on collaborative learning and investigate motivational factors for information exchange in social spaces. Internal motivation, gain of prestige, quality and quantity of the content, and procedural fairness were found as strongest factors motivating participation in a system. Time and effort requirements for contributions as well as fear of personal feedback are the strongest factors that might hinder contributions.

Chen and Jang [37] investigated motivation in online learning environments taking the selfdetermination theory into account. Learners may have internal reasons such as interest, joy, or selffulfilment. External reasons could be fear of being outdated, coerced by teachers, or pressured by examinations.

Tour [38] investigated self-initiated personal learning networks of teachers. Such networks, e. g., initiated on Twitter, can be used to share ideas about teaching, learning and classroom management, find relevant materials, and to obtain feedback and emotional support from other teachers. Teachers are motivated to improve themselves and to extend their knowledge related to teaching with digital technologies.

Looking at the platforms themselves, the primary factors of adoption are perceived usefulness and perceived ease of use $[39,40]$. Tsai and Bagozzi [41] argue that a we-intension and the feeling of belongingness to the platform lead to higher contribution rates.

\section{RESEARCH SURVEY FOR IDENTIFYING SUCCESS FACTORS}

\subsection{Methodology}

It is essential to understand the factors that affect adoption both at the individual level as well as at the environmental/organizational level before implementing a DLP [40]. If these factors are understood, it is easier to successfully implement and use such systems in practice. In order to identify success factors, we conducted a survey.

The main goal of the survey is twofold. On the one hand, there are different perceptions of what constitutes digital learning and teaching. Thus, it is important to know and to analyse how the users of educational technologies define what digital learning and teaching is, at least in the settings of a specific university. On the other hand, the survey seeks to explore participants' subjective opinions 
about which factors make educational technologies successful. Which success factors affect their motivation to use these technologies and in which degree?

The questionnaire was developed after considering the morphological box presented in Section 2.2 and the related literature. It consisted of five questions regarding what comprises e-learning, what makes it successful and the role of the survey participant in e-learning (learner, teacher, administrative, other). The invitation to participate was sent to all students and faculty members of the Berlin School of Economics and Law. The students attend lectures directly in the classroom or partly via distance learning. The LMS Moodle is widely used for supporting the lectures. Teachers use the system to provide slides and additional teaching material for the learners.

Data was collected over two weeks in December 2018. A total of 486 responses were received. Almost ten times more learners than teachers participated in the survey: $450(92.6 \%)$ vs. $46(9.5 \%)$, respectively. Some participants chose more than one user category. This might be the case of those using educational technologies not only for teaching but also for learning in other contexts, for example. 16 people (3.3\%) belong to the e-learning service and support user category. No other role was mentioned by the participants.

\subsection{Results and discussion}

First, respondents were presented with 19 propositions of what can be considered when defining digital learning and teaching. The idea behind is to tackle different dimensions and determinants of a DLP (see Section 2.2) from the respondents' point of view. They had to evaluate their level of agreement with each proposition by selecting an option from a five-point Likert rating scale ranging from "Not suitable at all" (out of scope) over "Somewhat suitable" or "Relatively suitable" (potential, possible) to "Very suitable" or "Totally suitable" (imperative, mandatory). The option "I don't know" was also available. Fig. 3 shows the top 10 propositions according to what respondents consider it should be imperative or mandatory.

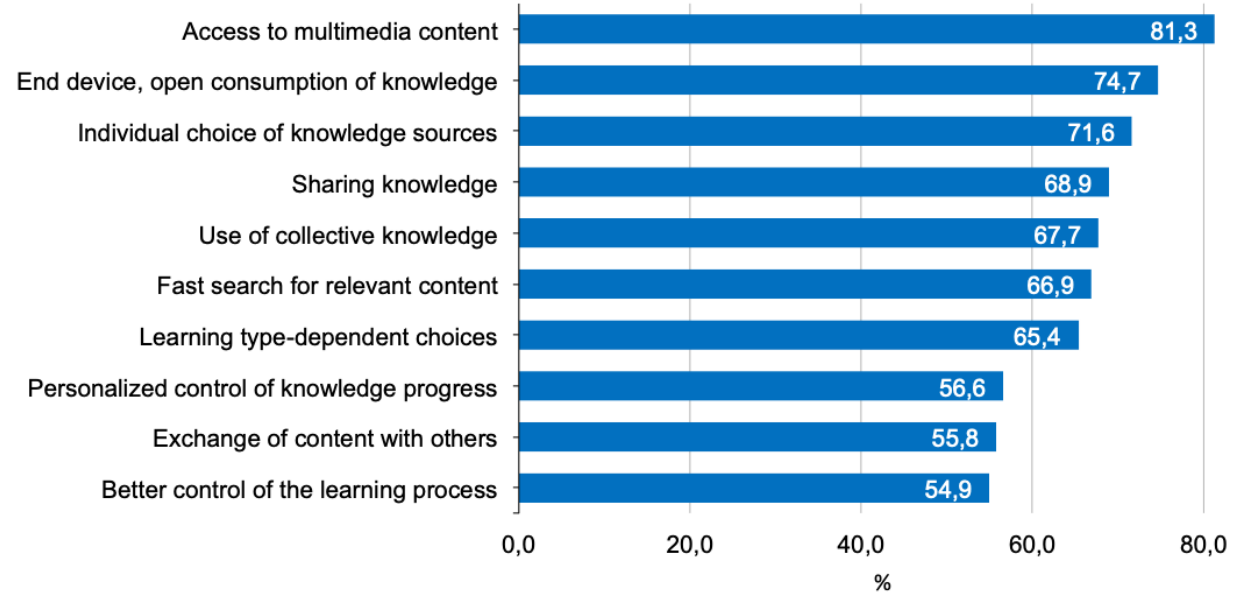

Figure 3. Top 10 defining characteristics of digital learning and teaching.

The top three defining characteristics of digital learning and teaching, i.e., what respondents consider to be mandatory or imperative for such a technology, are: easy access to $(81.3 \%)$, individual $(74.7 \%)$, and flexible consumption of $(71.6 \%)$ knowledge, in this order. The next defining characteristics in ranking are sharing knowledge, use of collective knowledge, and fast search of relevant content, with more than two-thirds of responses collected for each of them. Compared to the morphological box depicted in Fig. 2, we can recognize the determinants of DLPs in the answers shown in Fig. 3. Some of them are even consistent with findings from other works [36, 39, 40].

The least agreed upon defining characteristics are, in decreasing order: knowledge contest or competition (11.1\%), content recommendation (9.9\%), and receiving feedback (9.9\%). All in all: interaction with others, like in usual social networks, might not characterize an educational technology for learning and teaching, according to the participants. This would be consistent with the top three characteristics mentioned above. Learning is perceived as a very individual activity (notice that the big majority of respondents are learners). In other words, learners might find no motivation to use educational technologies when the intention is to interact with others online. The next least important 
defining characteristic (fourth least in ranking) reinforces these thoughts: there is almost no interest in creating communities on a given topic. Because most of the students that answered the questionnaire are attending classroom lectures, they meet their fellow students daily face-to-face. An additional online interaction might therefore be not necessary.

Examples of other defining characteristics suggested by respondents in the optional, open-ended question are an adequate mastery of digital skills by the teachers (this characteristic was mentioned several times), the practical relevance of the content, a necessary combination with face-to-face teaching, and gamification activities that encourage participation.

Further, respondents were presented with 17 factors that could make educational technologies successful. This time, respondents were confronted with different motivation factors (see Section 3.3). They had to evaluate their level of agreement with each success factor again by selecting an option from a five-point Likert rating scale ranging from "Not important at all" (out of scope) over "Somehow important" or "Relatively important" (potential, possible) to "Very important" or "Extremely important" (imperative, mandatory). The option "I don't know" was also available. Fig. 4 shows the results that were obtained for the top 10 success factors. Again, the scores for imperative or mandatory factors are considered.

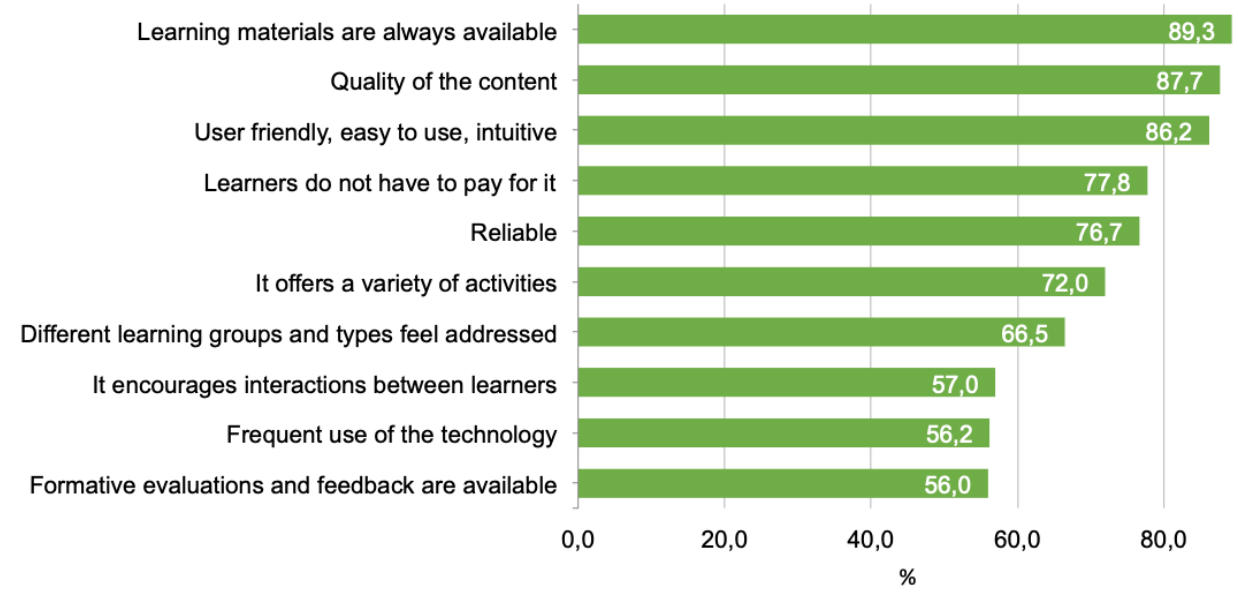

Figure 4. Top 10 Success factors of digital learning and teaching technologies.

Additionally, survey participants could mention other success factors not contained on the list that was presented in an open-ended answer. A total of 99 suggestions were received: 83 from learners, 10 from teachers, and 6 from people that teach and also learn using educational technologies (they are probably teachers in the first place). Finally, participants could also provide feedback on digital learning and teaching technologies. A total of 42 suggestions, including literature sources, were collected this way.

Regarding the success factors of digital learning and teaching technologies, participants to the survey consider that the most important factors are the content being always available $(89.3 \%)$, of high quality $(87.7 \%)$, and easy to use $(86.2 \%)$, in this order. This could mean that the most important factors comprise the technology as a place to store meaningful information and to use it easily (which is consistent with the findings in $[39,40]$. For teachers, however, the quality of the information that is provided plays the most important role in the success of the technology. This is of secondary importance for learners (or people that use the technology for learning). Quality of content was already a motivation factor found by [36].

The next important factors that make digital learning and teaching successful, according to the participants, sum up to a free $(77.8 \%)$, safe $(76.7 \%)$, multi-purpose $(72 \%)$, and multi-user $(66.5 \%)$ technology. Teachers or people that use the technology for teaching, when analysed separately, add a new success factor this time. They also consider the factor "It encourages interactions between learners," as being important to the success of an educational technology; however, for learners, this is the fourth least important factor (66.7\% for teachers vs. $51.9 \%$ for learners).

Success factors that are not important at all to the participants (they are out of scope) are: better grades $(8 \%)$, the institution's reputation $(8 \%)$, and the teacher's reputation $(7.2 \%)$, in decreasing order. When analysed separately, teachers invert the order of the least important success factors, add a new 
one, and assign much higher percentages to them than learners do. Teachers think that the reputation of the institution (25\%), followed by the reputation of the teacher (16.7\%), are the least important factors contributing to the success of an educational technology. Furthermore, interactions between teachers $(12.5 \%)$ and better grades (12.5\%) are not important to them. This is not in line with previous research where examination pressures [37] or gain of prestige [36] were found as relevant factors. Moreover, interactions between teachers are not favoured, contrary to the findings in [38].

\section{CONCLUSIONS}

Against the background of the considerations on the complexity of DLPs and previous studies on the motivation of participants, the presented study shows that the expectation of successful learning environments strongly depends on the participants' personal, social, and institutional backgrounds, among other aspects. Some factors, such as the interaction between the learners or the reputation of a teacher, lose their importance because the study model already requires physical presence or there is no choice regarding the teacher. It is also important to know what kind of technology digital learners possess and use for learning in order to customize and design appropriate digital tools for them [42]. We can think of the best educational technology with the best intentions, but if it cannot be used in practical settings, then we would never reach our goals as expected.

The design of a DLP should then consider not only the factors that might make it successful but also the inhibiting factors in terms of using it. Especially, the success factors analysed in this paper could be thought of as a starting point or initial approach for the conceptualisation of a successful, humancentred DLP. Our results show that there is no one-size-fits-all approach, but, in order to be successful, a DLP has to be developed individually based on the participants' backgrounds, needs, and behaviour.

\section{REFERENCES}

[1] OECD, "Students, computers and learning. Making the connection," Pisa, Paris: OECD Publishing, 2015. https://doi.org/10.1787/9789264239555-en.

[2] C. Lemke and W. Brenner, "Einführung in die Wirtschaftsinformatik, Band 1: Verstehen des digitalen Zeitalters," Berlin, Heidelberg: Springer Gabler, 2015.

[3] C. Lemke, K. Kirchner, and B. Rohner, "Es ist Vorlesung und keiner geht hin," in Proceedings of INFORMATIK 2017 (M. Eibl and M. Gaedke eds.), pp. 255-266, Gesellschaft für Informatik, Bonn, 2017.

[4] R. Luppicini, "A Systems Definition of Educational Technology in Society," Educational Technology \& Society, vol. 8, no. 3, pp. 103-109, 2005.

[5] Y.-C. Hsu, J.-L. Hung, and Y.-H. Ching, "Trends of educational technology research: more than a decade of international research in six SSCl-indexed refereed journals," Education Tech Research Dev, vol. 61: pp. 685-705, 2013.

[6] A. Januszewski and M. Molenda, "Educational technology: A definition with commentary," New York: Routledge, 2008.

[7] F. Von Gross, D. M. Meister, and U. Sander, "Medienpädagogik - ein Überblick," Weinheim: Beltz Juventa, 2009.

[8] M. Kerres, "Mediendidaktik: Konzeption und Entwicklung digitaler Lernangebote," 5 th expanded edition, Oldenbourg: De Gruyter Studium, 2018.

[9] M. Kerres and A. Preussler, "Mediendidaktik," in Medienpädagogik - ein Überblick (F. von Gross, D. M. Meister, and U. Sander eds.), pp. 32-48, Weinheim: Beltz Juventa, 2009.

[10] K. Schneider, "Educational Technology," EduTech Wiki, 2018. Retrieved from http://edutechwiki.unige.ch/en/Educational_technology.

[11] B. Weidenmann, "Multimedia": Mehrere Medien, mehrere Codes, mehrere Sinneskanäle?," Unterrichtswissenschaft, vol. 25, no. 3, pp. 197-206, 1997.

[12] S. Strecker, D. Kundisch, F. Lehner, J. M. Leimeister, and P. Schubert, "Higher Education and the Opportunities and Challenges of Educational Technology," Bus Inf Sys Eng, vol. 60, no. 2, pp. 181-189, 2018. 
[13] T. C. Reeves, "A Model of the Effective Dimensions of Interactive Learning on the World Wide Web," in Proceedings of Interaktiviinen Teknologia Koulutuksessa (J. Veteli Ed.), pp. 86-93, Hameenlinna, Finland, 2005.

[14] M. Kenney and J. Zysman, "The Rise of the Platform Economy," Issues in Science and Technology, vol. 32, no. 3, pp. 61-69, 2016.

[15] A. Hagiu and J. Wright, "Multi-sided Platforms," International Journal of Industrial Organization, vol. 43, pp. 162-174, November 2015.

[16] J.-C. Rochet and J. Tirole, "Platform competition in two-sided markets," Journal of the European Economic Association, vol. 1, no. 4, pp. 990-1029, 2003.

[17] J.-C. Rochet and J. Tirole, "Defining Two-Sided Markets," mimeo, IDEI, Toulouse, 2004.

[18] L. Daniela and A. Rūdolfa, "Learning Platforms: How to Make the Right Choice," in Didactics of Smart Pedagogy, pp. 191-209, Cham, Switzerland: Springer, 2019.

[19] K. Jona and S. Naidu, "MOOCs: emerging research," Distance Education, vol. 35, no. 2, pp. 141-144, 2014 https://doi.org/10.1080/01587919.2014.928970.

[20] G. Conole, "MOOCs as disruptive technologies: strategies for enhancing the learner experience and quality of MOOCs," RED, Revista de Educación a Distancia, vol. 50, no. 2, 2016.

[21] C. Pappas, "What Is A Learning Management System? LMS Basic Functions And Features You Must Know," eLearning Industry, 2017. Retrieved from https://elearningindustry.com/.

[22] Z. Zhu, Y. Sun, and P. Riezebos, "Introducing the smart education framework: core elements for successful learning in a digital world," Int. J. Smart Technol. Learn., vol. 1, no. 1, p. 53-66, 2016.

[23] G. Faustmann, C. Lemke, und K. Kirchner, "Und was lehrst Du? - Entwurf einer digitalen Plattform für Lehrende," in Angewandte Forschung in der Wirtschaftsinformatik 2018: Tagungsband zur 31. AKWI-Jahrestagung (T. Barton, F. Herrmann, V. Meister, C. Müller, and C. Seel eds.), pp. 72-82, Heide: mana-Buch, 2018.

[24] G. F. Knolmayer, "E-learning objects," Wirtschaftsinformatik, vol. 46, no. 3, pp. 222-224, 2004.

[25] S. Seufert, "Cultural perspectives," Handbook on information technologies for education and training, pp. 411-421, Berlin, Heidelberg: Springer, 2002.

[26] P. Baumgartner and M. Kalz, "Content Management Systeme aus bildungstechnologischer Sicht," in Content Management Systeme für e-Education: Auswahl, Potenziale und Einsatzmöglichkeiten (P. Baumgartner, H. Häfele, and K. Maier-Häfele eds.), pp. 37-66, Innsbruck: Studienverlag, 2004.

[27] M. G. Moore, "Three Types of Interaction," American Journal of Distance Education, vol. 3, no. 2, pp. 1-7, January 1989.

[28] Y. Lou, R. M. Bernard, and P. C. Abrami, "Media and Pedagogy in Undergraduate Distance Education: A Theory-based Meta-Analysis of Empirical Literature," Educational Technology Research and Development, vol. 54, no. 2, pp. 141-176, 2006.

[29] C. L. de Marcos, J. J. Pages, Martínez, and J. A. Gutiérrez, "Reflections on E-learning Lifecycle and Learning Objects Lifecycle," in Proc. of International Technology, Education and Development Conference, INTED2007, Valencia, Spain, pp. 7-9, March 2007.

[30] O. N. Gustun and N. V. Budaragin, "The lifecycle of e-learning course in the adaptive educational environment," in AIP Conference Proceedings, vol. 1797, p.p. 020004-1-5, 2017.

[31] E. L. Deci and R. M. Ryan, "The 'What' and 'Why' of Goal Pursuits: Human Needs and the Self-Determination of Behavior," Psychological Inquiry, vol. 11, no. 4, pp. 227-68, 2000.

[32] K. Kreijns, F. Van Acker, M. Vermeulen, and H. van Buuren, "What stimulates teachers to integrate ICT in their pedagogical practices? The use of digital learning materials in education," Comput. Hum. Behav., vol. 29, no. 1, pp. 217-225, Jan. 2013.

[33] F. Van Acker, H. van Buuren, K. Kreijns, and M. Vermeulen, "Why teachers use digital learning materials: The role of self-efficacy, subjective norm and attitude," Educ. Inf. Technol., vol. 18, no. 3, pp. 495-514, Sep. 2013. 
[34] I. Govender, "The learning context: Influence on learning to program," Comput. Educ., vol. 53, no. 4, pp. 1218-1230, Dec. 2009.

[35] K. M. Y. Law, V. C. S. Lee, and Y. T. Yu, "Learning motivation in e-learning facilitated computer programming courses," Comput. Educ., vol. 55, no. 1, pp. 218-228, Aug. 2010.

[36] C. Matschke, J. Moskaliuk, F. Bokhorst, T. Schümmer, and U. Cress, "Motivational factors of information exchange in social information spaces", Computers in Human Behavior, vol. 36, pp. 549-58, 2014.

[37] K.-C. Chen and S.-J. Jang, "Motivation in online learning: Testing a model of self-determination theory," Computers in Human Behavior, vol. 26, pp. 741-752, 2010.

[38] E. Tour, "Teachers' self-initiated professional learning through Personal Learning Networks," Technology, Pedagogy and Education, vol. 26, no. 2, pp. 179-192, 2017.

[39] F. D. Davis, "Perceived usefulness, perceived ease of use, and user acceptance of information technology," MIS Quarterly, vol. 13, no. 3, pp. 319-340, 1989.

[40] R. Panigrahi, P. R. Srivastava, and D. Sharma, "Online learning: Adoption, continuance, and learning outcome-A review of literature," International Journal of Information Management, vol. 43, pp. 1-14, 2018.

[41] H. T. Tsai and R. P. Bagozzi, "Contribution behavior in virtual communities: Cognitive, emotional, and social influences," MIS Quarterly, vol. 38, no. 1, pp. 143-163, 2014.

[42] A. Jefferies, D. Monett, and D. Kornbrot, "Digital Learners in Higher Education: Exploring Technology Ownership Patterns and Learning Engagement," in Proceedings of the 15th European Conference on eLearning, ECEL 2016 (J. Novotna and A. Jancarik eds.), pp. 315322. Reading, UK: ACPI, Academic Conference Publishing International, 2016. 